A. Baragunov

\title{
IMPROVING MILK PRODUCTION TECHNOLOGY ON MOUNTAIN FARMS
}

Key words: dairy farming; mountain environments; machine milking; energy-saving technology.

\author{
Authors' personal details
}

\begin{abstract}
Albert Baragunov, Candidate of Technical Sciences, Associate Professor at the Department of Energy Supply of Enterprises, Kabardino-Balkar State Agrarian University, 360030, Nalchik, Prospect Lenina, 1B, e-mail: baragun_albert@mail.ru.

The paper presents an alternative dairy farming technology that can be used on a mountain farm featuring free range and tie-up practices. The free range and tie-up farming practices are regular on dairy farms of the North Caucasus republics. During the warm season, the livestock is moved to the mountain pastures of the region, where the atmospheric pressure is low. The factor has a negative effect on the operation of milking equipment. In addition, the risk of injuring the secretory organs increases resulting in lower milk quality and subsequently bringing about the cow culling. Machines consume much of energy resources, which is especially true for mountain pastures, thereby reducing the profitability of the dairy industry as a whole. The study aimed to

improve the design of machines for cow milking, manure collection, and waste disposal. The developed design of milking machines showed better adaptability to atmospheric pressure in mountain regions, low load mode of operation and $40 \%$ lower risks associated with the injuries of the cows' secretory organs. The efficiency of the vacuum plant was increased due to the vacuum pressure. The high efficiency of the vacuum plant produced higher milking velocity. In turn, the energy resources spent for machine milking were saved up to $3000 \mathrm{~kW}$ per year. The individual manure collecting units make it possible to manage without the energy-consuming manure collecting equipment, thereby increasing the energy-saving production ratio.
\end{abstract}

(C) Барагунов А.Б.

УДК 619:612.32:591.531.2

DOI: 10.31563/1684-7628-2020-54-2-55-60

В.В. Гимранов, И.М. Абызгильдина

\section{НЕПРОХОДИМОСТЬ КИШЕЧНОГО ТРАКТА У МЕЛКИХ ДОМАШНИХ ЖИВОТНЫХ: ДИАГНОСТИКА И ЛЕЧЕНИЕ}

\section{Ключевые слова: непроходимость; кищечник; желудок; заворот; инородное тело; рвота.}

Введение. Непроходимость кишечного тракта у плотоядных относится к широко распространенной патологии и является одной из актуальных проблем незаразных болезней у мелких домашних животных. Однако ее диагностика усложняется симптомами и клиническими признаками, характерными для инфекционных и паразитарных заболеваний этих животных. В связи с тем, что течение этих патологий протекает остро, возникает экстренная необходимость дифференциальной диагностики данного процесса с незамедлительным симптоматическим лечением для стабилизации состояния животного перед оперативным вмешательством [1-6]. Как отмечают многочисленные авторы, причины возникновения непроходимости ки- шечного тракта у мелких домашних животных носят многофакторный характер: патология обмена веществ, особенно у молодых животных, которая проявляется в виде аллотриофагии - извращения вкуса и аппетита, что способствует попаданию инородных предметов в желудочнокишечный тракт; заворот кишечника, сопровождающийся образованием спаек и частичной непроходимостью; инвагинация кишечника; новообразования; грыжи. При постановке диагноза проводятся клинические исследования, рентгенодиагностика, в том числе с использованием контрастных веществ, УЗИ-диагностика. В связи с многообразием причин развития и неоднозначностью клинических признаков проявления у мелких домашних животных непроходи- 
мости кишечника, развивающейся с симптомами, сходными с болезнями как незаразной, так и инфекционной и паразитарной этиологии, изучение данной патологии является актуальной для ветеринарной науки и практики [7-13].

Цель исследований - выявить распространенность у мелких домашних животных и определить эффективные методы диагностики, дифференциальной диагностики и лечения непроходимости кишечного тракта.

Материал и методы исследований. Исследования проводились на кафедре морфологии, патологии, фармации и незаразных болезней ФГБОУ ВО Башкирский ГАУ и в ветеринарных клиниках г. Уфы. Животные поступали в клиники со сроками болезни от одних до нескольких суток, причем некоторые животные уже проходили обследование и лечение в других клиниках по месту жительства. Основными симптомами поступивших больных животных являлись угнетение, рвота, отказ от корма, отсутствие дефекации или ее неполноценность,

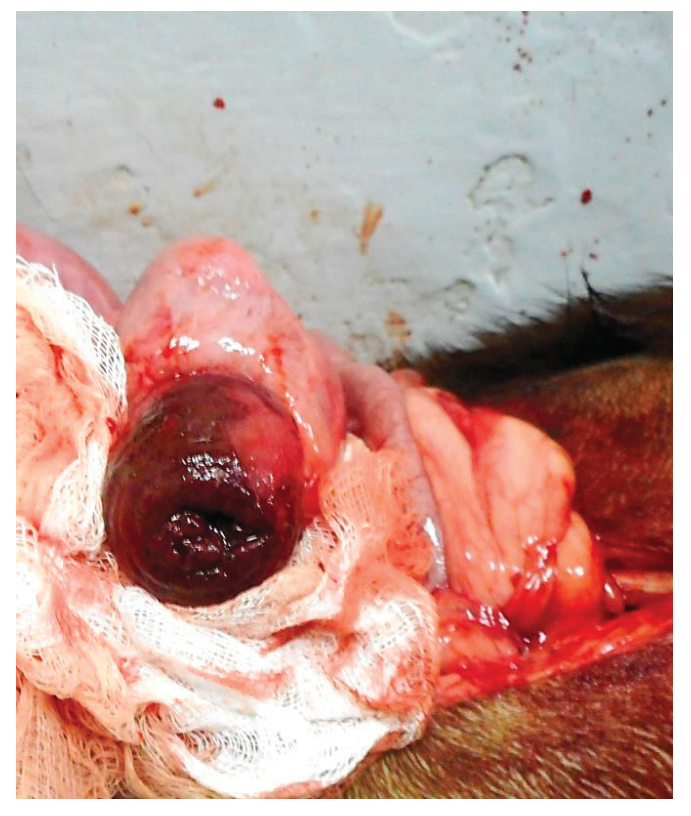

Рисунок 1

Инвагинация кишечника у собаки

В описываемых клинических случаях непроходимость кишечного тракта была обусловлена различными причинами на всем его протяжении, начиная с ротовой полости до конечного отдела толстой кишки. У всех животных после окончательного установления диагноза проводили оперативное лечение, все операции проводились под общим наркозом с применением препаратов «Ксила» и «Золетил». В зависимости от нахождения инородного тела по ходу пищеварительного тракта осуществляли соответствующий оперативный доступ. болезненность при пальпации области живота, пустой кишечник или слабое его заполнение, подозрение на наличие нехарактерных включений по ходу кишечника (инородных тел, инвагинаций, новообразований и пр.). Результаты исследований получены с использованием проведенных клинических исследований, УЗИ и рентгенодиагностики, в том числе с применением рентгеноконтрастных веществ.

Результаты исследований. Исследования проведены у 16 собак и 25 кошек со случаями непроходимости, которым было проведено оперативное лечение. У двух собак после операции прогноз был неблагоприятный. В первом случае отмечали инвагинацию кишечника (рисунок 1), во втором - инородные тела в кишечнике вследствие извращения аппетита (рисунок 2). У одной кошки из 25 случаев была диагностирована непроходимость пищевода (стеноз) (рисунок 3) с осторожным прогнозом, при этом оперативное вмешательство по техническим причинам не проводилось.

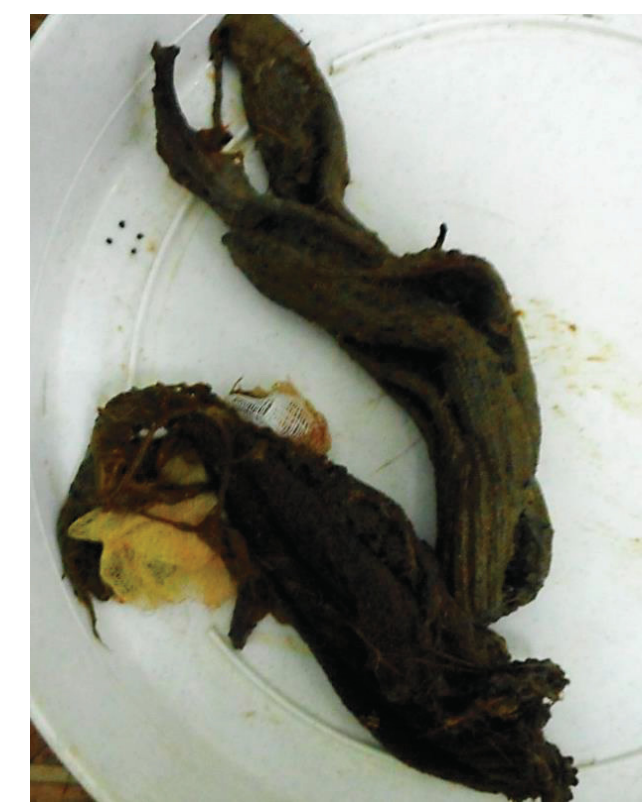

Рисунок 2

Инородные тела, извлеченные

из кишечника щенка алабая (монтажные перчатки)

Инородные тела в ротовой полости устанавливали клинически, фиксировали зевниками, извлечение инородных тел в ротовой полости проводили под местным обезболиванием или наркозом.

При локализации инородного тела в пищеводе, подтвержденной рентгенологически (рисунок 4.1), делали разрез кожи в области шеи слева, затем пищевода, извлекали инородное тело (рисунок 4.2). После этого накладывали двухэтажный шов, первый - на пищевод, второй наружный узловатый - на кожу. 


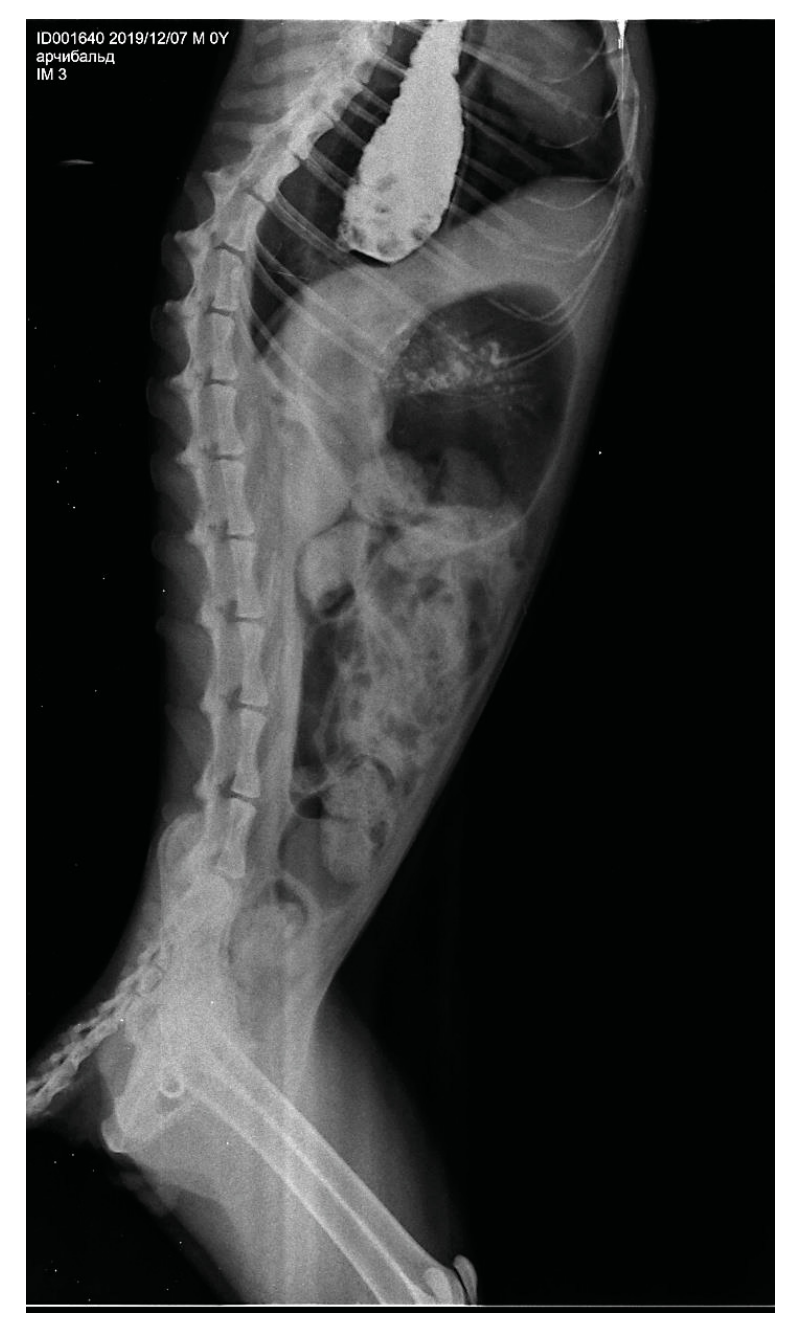

Рисунок 3

Непроходимость пищевода. Скопление контрастного вещества в пищеводе

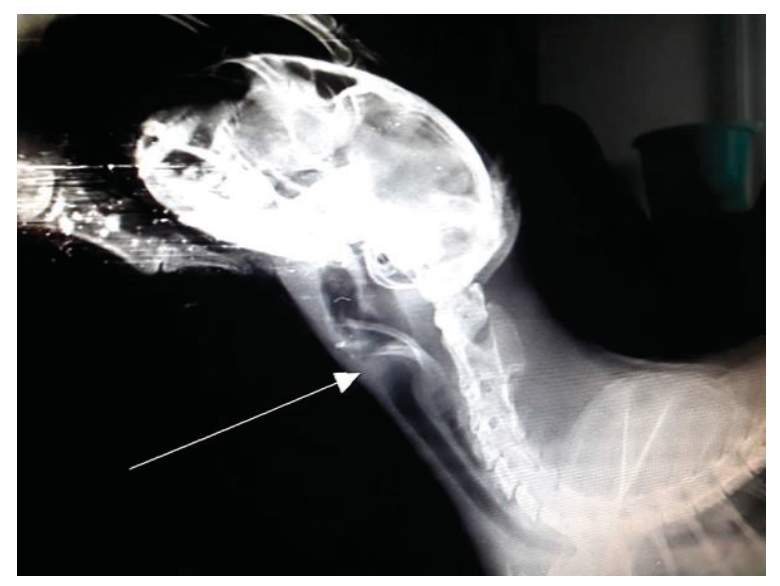

Рисунок 4.1

Рентген. Инородные тела в пищеводе у кошки

Учитывая клинические признаки, окончательный диагноз нахождения инородных предметов в желудке, кишечнике или другие факторы, которые вызывали непроходимость, устанавливали рентгенологически.

Особую опасность у кошек представляет проглатывание швейных и иных нитей, которые, попав в желудок, формируют инородное тело в

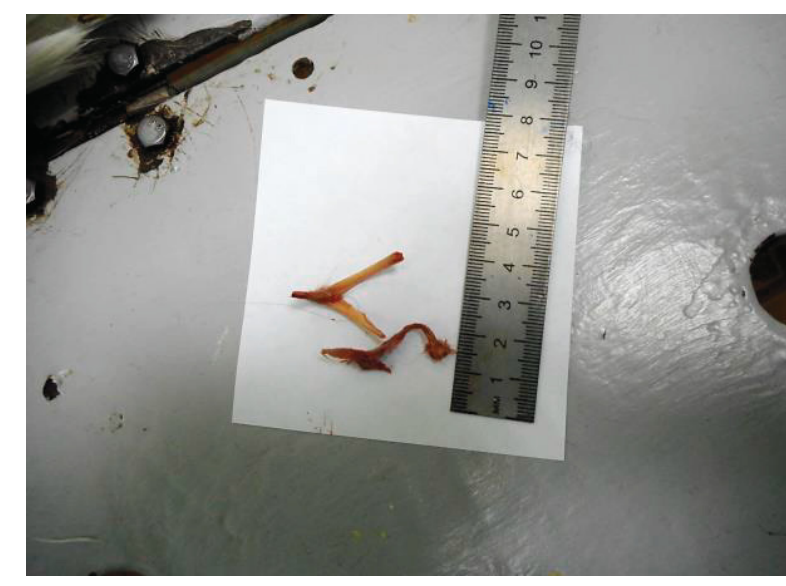

Рисунок 4.2

Извлеченные из пищевода кошки куриные кости

виде клубка в смеси с плотными элементами желудочного содержимого; при благоприятном исходе такой клубок проникает в кишечник и, беспрепятственно продвигаясь под влиянием перистальтики, выделяется вместе с каловыми массами. В некоторых случаях часть нити из этого клубка проходит в кишечник, а часть остается в желудке, при этом его дальнейшее продвижение 
становится невозможным. В результате между клубком в желудке и зафиксировавшимся концом нити в кишечнике возникает натяжение, которое приводит к периодическому складыванию зафиксированной части кишечника в «гармошку» под действием естественной перистальтики. Создающееся при этом трение приводит к прободению стенки кишечника в области прилегания к брыжейке. Причем количество таких точек прободения кишечника может достигать от 2-3 до 10-15 и более в зависимости от длины нити и части кишечника, формирующей «гармошку». Процесс прободения кишечника протекает в течение определенного периода времени, поэтому в процессе операции у животного могут наблюдаться признаки перитонита. В связи с этим, если количество точек прободения не более трех, то при проведении операции герметичность кишечника обеспечивается наложением двухэтажного кишечного шва, а если их больше, предлагаем проводить резекцию поврежденного фрагмента кишечника (рисунок 5), т. к. в ином случае не может быть обеспечена гарантированная герметичность всех участков прободения.

Затруднения вызывают диагностика и дифференциальная диагностика непроходимости кишечника у плотоядных, связанной с заворотом кишечника, образованием спаек, инородными телами в желудке, грыжами. Заворот кишечника, как правило, осложняется образованием спаек и развитием частичной или полной непроходимости.

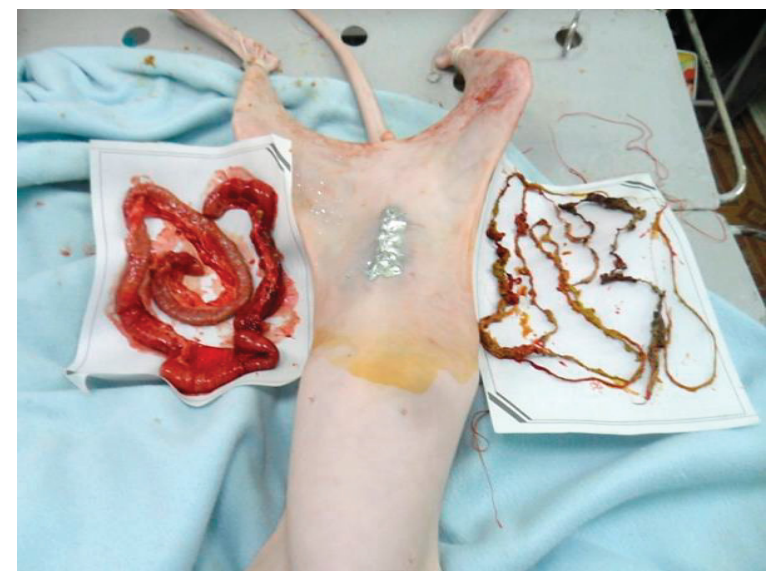

Рисунок 5

Синтетическая нить в кишечнике у кошки породы сфинкс. Резекция части кишечника, подвергнутой прободениям. Синтетическая нить, извлеченная из кишечника

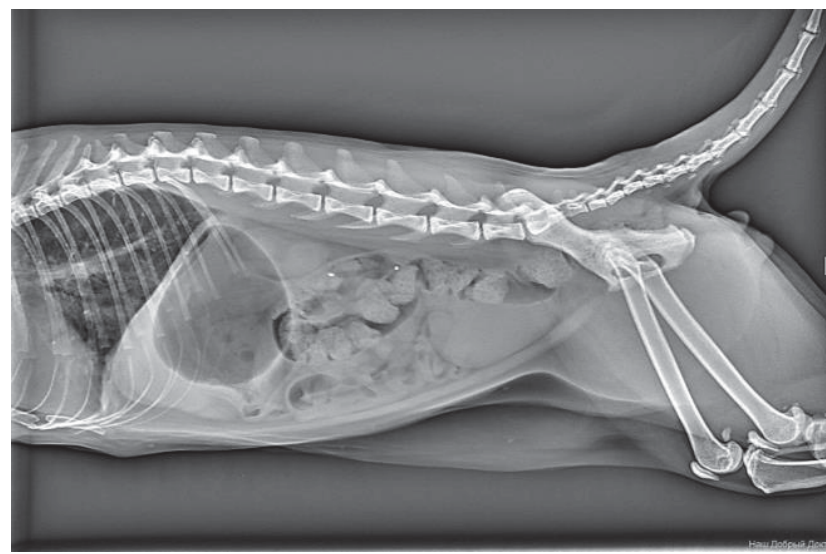

Рисунок 6

Полная непроходимость кишечника у кошки вследствие заворота кишечника и спаечной болезни.

Переполнение газами желудка, желудок грушевидной формы

При этом, как правило, желудок переполняется газами и приобретает грушевидную форму (рисунок 6), кишечник до места непроходимости также переполнен газами, после этого участка он спавшийся. При таком рисунке желудка на рентгеновском снимке мы рекомендуем использовать для диагностики и диффе- ренциальной диагностики непроходимость кишечника у мелких домашних животных.

В процессе операции в первую очередь ликвидируются спайки. Для этого используется игла Дешана, с помощью которой лигатура подводится под спайку, игла удаляется, оставшаяся лигатура рассекается пополам, оставшиеся 
концы разводятся и завязываются в узлы, между которыми рассекается спайка, такая техника позволяет избежать кровотечения после рассечения спаек. При наличии инородных тел в желудке и кишечнике их удаляют; выбор линии разреза определяется местом, где находится меньшее количество кровеносных сосудов. После рассечения тканей и удаления инородных предметов края ран сближают и на них накладывают кишечный жом, что предотвращает сужение просвета ран полых органов и создает в последующем оптимальные условия для наложения швов. Затем на раны кишечника и желудка накладывают двухэтажные швы. После этого определяют состояние кишечника, руками перебирая петли на всем его протяжении. После ликвидации заворота или удаления инородного тела кишечника, вызывающего непроходимость, кишечник начинает постепенно заполняться на всем протяжении газами. Лапаротомию завершают наложением двухэтажного шва на брюшную стенку.

Вывод. Определяющими при непроходимости кишечника у мелких домашних животных является ранняя и дифференциальная диагностика этой патологии и ее неотложное оперативное лечение.

\section{Библиографический список}

1. Андреенко, А.А. Особенности диагностики хиатальных грыж у мелких домашних животных [Текст] / А.А. Андреенко, С.В. Позябин // Ветеринария, зоотехния и биотехнология. 2014. № 5. C. 12-15.

2. Андреенко, А.А. Особенности диагностики непроходимости пищеварительного канала у кошек [Текст] / А.А. Андреенко, С.В. Позябин // Ветеринария, зоотехния и биотехнология. 2016. № 1. С. 6-11.

3. Гимранов, В.В. Болезни кишечника у плотоядных: диагностика и лечение [Текст] / В.В. Гимранов // Вестник Башкирского ГАУ. 2015. № 4. С. 37-40.

4. Гимранов В.В. Особенности цистотомии у собак при мочекаменной болезни [Текст] / В.В. Гимранов // Вестник Башкирского ГАУ. 2018. № 1. С. 58-62.

5. Медведева, Л.В. Сравнительная оценка биологической герметичности кишечного шва при однорядном и двухрядном способах закрытия операционной раны желудка у кошек [Текст] / Л.В. Медведева, Н.Б. Алексеенко // Вестник Алтайского ГАУ. 2014. № 4 (114). С. 122-126.

6. Медведева, Л.В. Исследование прочностных характеристик швов желудка и тонкокишечного анастомоза у кошек [Текст] / Л.В. Медведева, Н.Б. Алексеенко // Вестник Алтайского ГАУ. 2015. № 2 (124). С. 73-77.

7. Bischoff M.G. Radiographic techniques and interpretation of the acute abdomen. J. Clinical
Techniques in Small Animal Practice. 2003. № 18 (1). P. 7-19.

8. Garcia D.A., Froes T.R., Vilani R.G., Guérios S.D., Obladen A. Ultrasonography of small intestinal obstructions: A contemporary approach. Journal of Small Animal Practice. 2011. № 52 (9). P. 484-490.

9. Hall E. Rational selection of gastrointestinal drugs for cats and dogs. J. In Practice. 2002. № 24 (5). P. 242-249.

10. Hayes G. Gastrointestinal foreign bodies in dogs and cats: A retrospective study of 208 cases. Journal of Small Animal Practice 2009. № 50 (11). P. 576-583.

11. Nordquist B., Culp W.T. Focal and Linear Gastrointestinal Obstructions. J. Small Animal Soft Tissue Surgery. 2013. P. 360-373.

12. Papazoglou L.G., Patsikas M.N., Rallis T. Intestinal Foreign Bodies in Dogs and Cats. J. Compendium on Continuing Education for the Practicing Veterinarian. 2003. № 25 (11). P. 830-844.

13. Scotti S. Basic principles for foreign bodies in the digestive tract (Principe's de base lors de corps étrangers de l'appareil digestif). J. Point Veterinaire. 2015. № 46 (354). P. 22-24.

14. Tyrrell D., Beck C. Survey of the use of radiography vs. ultrasonography in the investigation of gastrointestinal foreign bodies in small animals. J. Veterinary Radiology and Ultrasound. 2006. № 47 (4). P. 404-408.

\section{Сведения об авторах}

1. Гимранов Валиян Валиуллович, доктор ветеринарных наук, профессор, профессор кафедры морфологии, патологии, фармации и незаразных болезней, ФГБОУ ВО Башкирский ГАУ, 450001, г. Уфа, ул. 50-летия Октября, 34, тел.: +7 (347) 228-08-57, e-mail: gim-val@mail.ru.

2. Абызгильдина Ильнара Минибулатовна, аспирант кафедры морфологии, патологии, фармации незаразных болезней, ФГБОУ ВО Башкирский ГАУ, 450001, г. Уфа, ул. 50-летия Октября, 34, тел.: +7 (347) 228-28-77. 
Изучена распространенность, клиническое проявление, диагностика, дифференциальная диагностика, лечение и профилактика непроходимости кишечника у мелких домашних животных. В статье дается обоснование необходимости проведения исследований в связи с широким распространением данной патологии у животных, протекающей с симптомами, сходными с болезнями незаразной, инфекционной и паразитарной этиологии. Исследования были проведены на 41 животном: 16 собак и 25 кошек, - это животные, которым было проведено оперативное лечение со случаями непроходимости. Установлено, что непроходимость кишечного тракта может быть обусловлена различными причинами на всем его протяжении, начиная с ротовой полости и оконечности прямой кишки. Основными симптомами поступивших больных животных являлись угнетение, рвота, отказ от корма, отсутствие дефекации или ее неполноценность, при пальпации области живота отмечалась болезненность, пустой кишечник или слабое его заполнение, в некоторых случаях по ходу кишечника отмечали наличие нехарактерных включений (подозрение на наличие инородных тел, инвагинаций, новообразований). Диагностику, дифференциальную диагностику проводили на основании клинических, гематологических, рентгенологических исследований, в том числе рентгенодиагностику с использованием контрастных веществ, УЗИ-диагностику. После установления диагноза проводилось оперативное лечение животного под наркозом, оперативный доступ обуславливался причиной, вызвавшей непроходимость кишечника, оперативное вмешательство проводилось с минимальным травмированием тканей, обеспечивались оптимальные условия для восстановления функциональности оперированных органов и тканей и их заживления. Таким образом, определяющими при непроходимости кишечника у мелких домашних животного являются ранняя диагностика и дифференциальная диагностика этой патологии и своевременное оперативное лечение.

V. Gimranov, I. Abyzgildina INTESTINAL OBSTRUCTION IN SMALL DOMESTIC ANIMALS:
DIAGNOSIS AND TREATMENT

\section{Key words: obstruction; intestines; stomach; inversion; foreign body; vomiting.}

\section{Authors' personal details}

1. Valijan Gimranov, Doctor of Veterinary Science, professor of the Department morphology, pathology, pharmacy and non-communicable diseases, Federal State Budgetary Educational Institution of Higher Education «Bashkir State Agrarian University», 450001, Ufa, 50-letiya Oktyabrya St., 34, e-mail: gim-val@ mail.ru.

2. Ilnara Abyzgildina, Post-graduate student of the department of morphology, pathology, pharmacy of non-communicable diseases, Federal State Budgetary Educational Institution of Higher Education «Bashkir State Agrarian University», 450001, Ufa, 50-letiya Oktyabrya St., 34, phone: +7 (347) 228-28-77.

We studied the prevalence, clinical manifestations, diagnosis, differential diagnosis, treatment and prevention of bowel obstruction in small domestic animals. The article substantiates the need for research in connection with the widespread occurrence of this pathology in animals with symptoms similar to diseases of an infectious, infectious and parasitic etiology. Studies were conducted on 41 animals, of which 16 dogs, 25 cats, these are animals who underwent surgical treatment with cases of obstruction. It has been established that intestinal obstruction may be due to various reasons along its entire length, starting with the oral cavity and its tip of the rectum. The main symptoms of the sick animals received were depression, vomiting, refusal to feed, lack of defecation or its inferiority, palpation of the abdomen showed pain, empty intestines or weak filling, in some cases, uncharacteristic inclusions were noted along the intestines (suspected presence of foreign bodies, intussusception, neoplasms). Diagnosis, differential diagnosis was carried out on the basis of clinical, hematological, radiological, including radiological diagnostics using contrast agents, ultrasound diagnostics. After the diagnosis was established, the animal underwent surgical treatment under anesthesia, surgical access was determined by the cause of intestinal obstruction, surgical intervention was performed with minimal tissue injury, and optimal conditions were provided for restoring the functionality of the operated organs and tissues and their healing. Thus, the early diagnosis and differential of this pathology and its timely surgical treatment is crucial for intestinal obstruction in small pets.

(с) Гимранов В.В., Абызгильдина И.М. 